Article

\title{
Controlled Growth of BiSI Nanorod-Based Films through a Two-Step Solution Process for Solar Cell Applications
}

\author{
Yong Chan Choi * ${ }^{*}$ and Eunjeong Hwang \\ Division of Energy Technology, DGIST, Daegu 42988, Korea; ejhwnag@dgist.ac.kr \\ * Correspondence: ycchoi@dgist.ac.kr; Tel.: +82-53-785-3735
}

Received: 28 October 2019; Accepted: 18 November 2019; Published: 20 November 2019

\begin{abstract}
Pb-based hybrid perovskite solar cells, despite their advantages, face challenges in commercialization. In recent years, Bi-based chalcohalides are being considered as potential alternative candidates, however, their current device efficiency remains unsatisfactory. Herein, a two-step solution method is developed and applied to the fabrication of BiSI films. The method consists of the formation of $\mathrm{Bi}_{2} \mathrm{~S}_{3}$ (step I) and its conversion to BiSI (step II). The $\mathrm{Bi}_{2} \mathrm{~S}_{3}$ was fabricated by a thiol-amine solution process and the BiSI conversion was achieved by chemical reaction between the as-formed $\mathrm{Bi}_{2} \mathrm{~S}_{3}$ and $\mathrm{BiI}_{3}$. It was found that the formation of BiSI was highly dependent on the Bi:S molar ratio of the $\mathrm{Bi}_{2} \mathrm{O}_{3}$-thiourea solution and the number of times of step I. The as-fabricated BiSI film had an optical band gap of $1.61 \mathrm{eV}$ and exhibited nanorod morphology. In addition, the electronic structure is explored and discussed for solar cells applications.
\end{abstract}

Keywords: bismuth chalcohalides; $\mathrm{BiSI} ; \mathrm{Bi}_{2} \mathrm{~S}_{3}$; solution process; thiol-amine; solar cells

\section{Introduction}

$\mathrm{Pb}$-based hybrid perovskites ( $\mathrm{Pb}$ perovskites) solar cells have several advantages, such as remarkable device efficiency, low-cost fabrication, and unique optoelectronic properties [1-3]. Thus, these are now considered to be the most promising substitute for $\mathrm{Si}$, widely used in the solar market. However, several challenges, such as scale-up and reproducibility issues in performance and the manufacturing process, as well as toxicity, must be solved to ensure success in the commercial market. Therefore, considerable efforts are being made to address these issues, or to develop tandem solar cells combined with other solar cells [1]. Researchers are also constantly looking for alternatives to $\mathrm{Pb}$ perovskites [4].

Recently, Bi-based chalcohalides, such as BiSI and BiSeI, are being considered as good alternatives because of their suitability as solar absorbers and stability [4-10]. In addition, these materials have a lower material cost compared to Pb perovskites (Supplementary Table S1) and low toxicity, due to non-toxic Bi content [5]. In particular, the solar cells based on them are expected to exhibit a high device efficiency because of the $\mathrm{ns}^{2}$ electronic configuration of $\mathrm{Bi}^{3+}$ (like $\mathrm{Pb}^{2+}$ of $\mathrm{Pb}$ perovskites), enabling defect-tolerant features [4-6]. Despite their great potential, little work has been carried out on solar cells, and their best reported device efficiency of $1.32 \%$ is unsatisfactory $[8,9]$. Therefore, further work is required to prove their potential as a photovoltaic material. However, fabrication methods suitable for solar cells are still lacking and have not been optimized to achieve the best performance.

BiSI and BiSeI have been fabricated using several methods, including a spray solution method [8], conversion reaction from $\mathrm{BiOI}$ particles under $\mathrm{H}_{2}(\mathrm{~S}, \mathrm{Se})$ gas [10], and a single source precursor solution method [9]. These methods are simple, versatile, and cost-effective because they are based on a solution process and performed at a low temperature below $300^{\circ} \mathrm{C}$. However, these techniques have not been 
fully validated as suitable methods for solar cells. Therefore, it is still necessary to develop an approach that can control the key variables, such as the crystal structure, morphology, and optoelectronic properties. We recently developed a simple solution method for typical Sb chalcohalides, SbSI, via a two-step process [11]: (i) formation of $\mathrm{Sb}_{2} \mathrm{~S}_{3}$ and (ii) its conversion to SbSI based on the simple chemical reaction of $\mathrm{Sb}_{2} \mathrm{~S}_{3}+\mathrm{SbI}_{3} \rightarrow 3 \mathrm{SbSI}$. With this method, the structure and morphology of SbSI were successfully controlled by tuning experimental parameters at each step. Given that SbSI is isostructural to BiSI [12], this two-step method can be easily applied to the BiSI fabrication by the following chemical reaction: $\mathrm{Bi}_{2} \mathrm{~S}_{3}+\mathrm{BiI}_{3} \rightarrow 3 \mathrm{BiSI}$. To this end, we chose the thiol-amine solution method for the $\mathrm{Bi}_{2} \mathrm{~S}_{3}$ fabrication in step I, which turned out to be a very effective approach of preparing various chalcogenides $[13,14]$.

In this work, we introduce the fabrication of BiSI films via our two-step solution process for solar cell applications. The $\mathrm{Bi}_{2} \mathrm{~S}_{3}$ is first fabricated using the $\mathrm{Bi}_{2} \mathrm{O}_{3}$-thiourea $\left(\mathrm{Bi}_{2} \mathrm{O}_{3}\right.$-TU) thiol-amine solution (step I), where $\mathrm{Bi}_{2} \mathrm{O}_{3}$ and TU are dissolved in 2-mercaptoethanol/ethanolamine (1/4 v/v) mixture. Then, it is converted to $\mathrm{BiSI}$ in the chemical reaction between as-formed $\mathrm{Bi}_{2} \mathrm{~S}_{3}$ and $\mathrm{BiI}_{3}$ (step II). The structures, absorption, and morphology are controlled by tuning the $\mathrm{Bi}: \mathrm{S}$ molar ratio of the $\mathrm{Bi}_{2} \mathrm{O}_{3}$-TU solution and the number of repetitions of step I. The morphology of as-fabricated BiSI film exhibits nanorods rather than a compact film. In addition, the electronic structure of BiSI is investigated and discussed for solar cell applications.

\section{Materials and Methods}

\subsection{Chemicals and Materials}

$\mathrm{Bi}_{2} \mathrm{O}_{3}(99.999 \%), \mathrm{BiI}_{3}(99.999 \%)$, 2-mercaptoethanol (98\%), and ethanolamine (98\%) were purchased from Alfa Aesar. Thiourea (TU; >99.0\%), N-methyl-2-pyrrolidinone (NMP; anhydrous, 99.5\%) and 1,2-dichlorobenzene (DCB; anhydrous 99\%) were purchased from Sigma-Aldrich. All chemicals were used as received without further purification. A pre-patterned F-doped $\mathrm{SnO}_{2}$ (FTO) substrate (Pilkington, TEC-8, $8 \Omega / \mathrm{sq}, 25 \mathrm{~mm} \times 25 \mathrm{~mm}$ ) with a FTO-etched surface area of $5 \mathrm{~mm} \times 10 \mathrm{~mm}$ was purchased from AMG (Korea). A stable $0.15-\mathrm{M} \mathrm{TiO}_{2}$ solution was purchased from ShareChem (Korea).

\subsection{Synthesis of $\mathrm{Bi}_{2} \mathrm{O}_{3}-\mathrm{TU}$ and $\mathrm{BiI}_{3}$ Solutions}

To synthesize the $\mathrm{Bi}_{2} \mathrm{O}_{3}$-TU solution based on $\mathrm{Bi}_{2} \mathrm{O}_{3}$ and $\mathrm{TU}, \mathrm{Bi}_{2} \mathrm{O}_{3}(0.3 \mathrm{mmol})$ was first dissolved in $1 \mathrm{~mL}$ of the thiol-amine mixture solvent (1:4 v/v of 2-mercaptoethanol:ethanolamine) and stirred for 1 day until a stable solution was obtained. Then, the desired amount of $\mathrm{Bi}_{2} \mathrm{O}_{3}$ solution was added to the TU-containing vial and stirred for 1 day to obtain the $\mathrm{Bi}_{2} \mathrm{O}_{3}-\mathrm{TU}$ solution with the desired $\mathrm{Bi}: \mathrm{S}$ molar ratio. For the synthesis of the $\mathrm{BiI}_{3}$ solution, 1 mmol of $\mathrm{BiI}_{3}$ was immediately dissolved in $1 \mathrm{~mL}$ of NMP by vigorous stirring. These synthetic procedures were performed in a glove box.

\subsection{Deposition of BiSI Thin Films}

The $0.15 \mathrm{M}-\mathrm{TiO}_{2}$ solution was spin coated on the FTO substrate at $5000 \mathrm{rpm}$ for $60 \mathrm{~s}$ and dried at $200{ }^{\circ} \mathrm{C}$ for $2 \mathrm{~min}$. Before deposition, the FTO substrate was cleaned with ultrasonic cleaner using acetone/ethanol and $\mathrm{UV} / \mathrm{O}_{3}$ cleaner [15] and the $\mathrm{TiO}_{2}$ solution was filtered using a $0.45 \mu \mathrm{m}$ polyvinylidene fluoride filter. The spin coating and drying steps were repeated 3 times. Then the as-deposited substrate was annealed at $500{ }^{\circ} \mathrm{C}$ in air for $30 \mathrm{~min}$, to form the anatase $\mathrm{TiO}_{2}$ blocking layer $\left(\mathrm{TiO}_{2}-\mathrm{BL}\right)$ on the FTO substrate. After the $\mathrm{TiO}_{2}-\mathrm{BL} / \mathrm{FTO}$ was cooled to room temperature, it was treated with a UV/O $\mathrm{O}_{3}$ cleaner for $20 \mathrm{~min}$ and immediately transferred to the glove box for the BiSI deposition.

BiSI thin films were deposited via two-step solution process in the glove box. In step I, as-prepared $\mathrm{Bi}_{2} \mathrm{O}_{3}$-TU solution was spin coated on $\mathrm{TiO}_{2}$-BL/FTO at $5000 \mathrm{rpm}$ for $70 \mathrm{~s}$ and dried at $200{ }^{\circ} \mathrm{C}$ for $5 \mathrm{~min}$ to form $\mathrm{Bi}_{2} \mathrm{~S}_{3} / \mathrm{TiO}_{2}$-BL/FTO. In step II, $\mathrm{BiI}_{3}$ solution was dripped on $\mathrm{Bi}_{2} \mathrm{~S}_{3} / \mathrm{TiO}_{2}-\mathrm{BL} / \mathrm{FTO}$ and spin coated with the same condition used in step $\mathrm{I}$. Then the $\mathrm{BiI}_{3}$-deposited $\mathrm{Bi}_{2} \mathrm{~S}_{3} / \mathrm{TiO}_{2}-\mathrm{BL} / \mathrm{FTO}$ was annealed at $200{ }^{\circ} \mathrm{C}$ for $30 \mathrm{~min}$ for the conversion of $\mathrm{Bi}_{2} \mathrm{~S}_{3}$ to BiSI. Finally, after the sample was cooled to room 
temperature, a NMP solvent was dripped and spin coated to remove any residual $\mathrm{BiI}_{3}$, which has not contributed to the BiSI formation, from the surface. Note that this final step is crucial for obtaining pure BiSI structures because a residual $\mathrm{BiI}_{3}$ causes the formation of undesirable phases (Supplementary Figure S1).

\subsection{Characterization}

The structure was measured with a multi-purpose X-ray diffractometer (Empyrean, Malvern Panalytical Ltd., Malvern, UK). Its structural phase was identified using software (X'Pert HighScore Plus) and indicated with a reference code number in the text. The absorption, morphology, and electronic structure were investigated using a UV-vis spectrophotometer (UV-2600, Shimadzu Corp, Kyoto, Japan), a field emission scanning electron microscope (S-4800, Hitachi Ltd., Tokyo, Japan), and an X-ray photoelectron spectrometer (ESCALAB 250Xi, Thermo Fisher Scientific Inc., MA, USA), respectively.

\section{Results and Discussion}

Figure 1a shows the schematic diagram of the BiSI fabrication process. The samples fabricated after step I and II exhibit orthorhombic $\mathrm{Bi}_{2} \mathrm{~S}_{3}$ (reference code: 98-061-7028) and orthorhombic BiSI (reference code: 98-002-3631) phases, respectively, as shown in Figure $1 \mathrm{~b}$. The optical band gaps $E_{G}$ of $\mathrm{Bi}_{2} \mathrm{~S}_{3}$ and $\mathrm{BiSI}$ are measured as $1.57 \mathrm{eV}$ and $1.61 \mathrm{eV}$, respectively. These are close to the reported values of 1.3-1.7 [16,17] and 1.5-1.8 eV [5-9,18,19], respectively. They have similar absorption edges around $1.6 \mathrm{eV}$ (Figure 1c), thereby showing a similar sample color, as shown in the inset image. These results indicate that BiSI film was successfully obtained from the $\mathrm{Bi}_{2} \mathrm{~S}_{3}$ film at a low temperature of $200{ }^{\circ} \mathrm{C}$ via our two-step solution process.
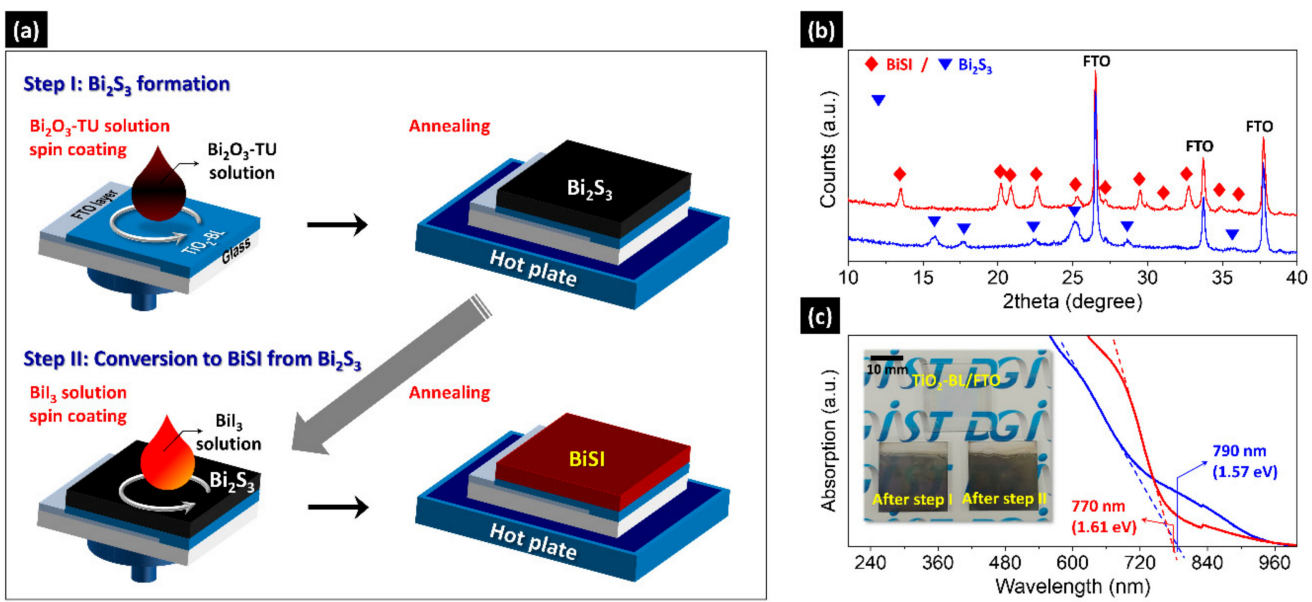

Figure 1. (a) Schematic diagram of the BiSI fabrication via the two-step solution process; (b) X-ray diffraction (XRD) patterns; (c) absorption spectra of the samples prepared after step I (blue line) and step II (red line). Inset in (c): photograph of $\mathrm{TiO}_{2}-\mathrm{BL} / \mathrm{FTO}$ and the two samples shown in $(\mathbf{b}, \mathbf{c})$. The samples were fabricated with the $\mathrm{Bi}_{2} \mathrm{O}_{3}-\mathrm{TU}$ solution of $\mathrm{Bi}: \mathrm{S}=1: 3$ molar ratio on $\mathrm{TiO}_{2}-\mathrm{BL} / \mathrm{FTO}$ substrates.

We found that the $\mathrm{Bi}: \mathrm{S}$ molar ratio of the $\mathrm{Bi}_{2} \mathrm{O}_{3}$-TU solution, used in step I, strongly affects the BiSI formation. We controlled the molar ratio of the solution based on the stoichiometric molar fraction of $\mathrm{Bi} / \mathrm{S}=1 / 1.5$ for $\mathrm{Bi}_{2} \mathrm{~S}_{3}$. Figure 2a shows XRD patterns of the BiSI thin films fabricated with the same conditions as the sample shown in Figure 1 but using $\mathrm{Bi}_{2} \mathrm{O}_{3}$-TU solution of different Bi:S molar ratios. All samples exhibit a pure orthorhombic BiSI phase but show a different intensity for each peak. To clearly display the difference in peak intensity of each pattern, we highlighted two peaks corresponding to (102) and (200) planes, shown in the inset image. The intensity of the two peaks gradually increased as the amount of $S$ increased in $\mathrm{Bi}: \mathrm{S}$, from 1:1 to 1:3, and then decreased at $\mathrm{Bi}: \mathrm{S}=1: 4$. The absorption spectra (Figure 2b) exhibited similar trends, where the absorption edges were the same 
regardless of the ratio and consistent with the value of Figure 1c. These results indicate that the Bi:S ratio plays a key role in BiSI formation.
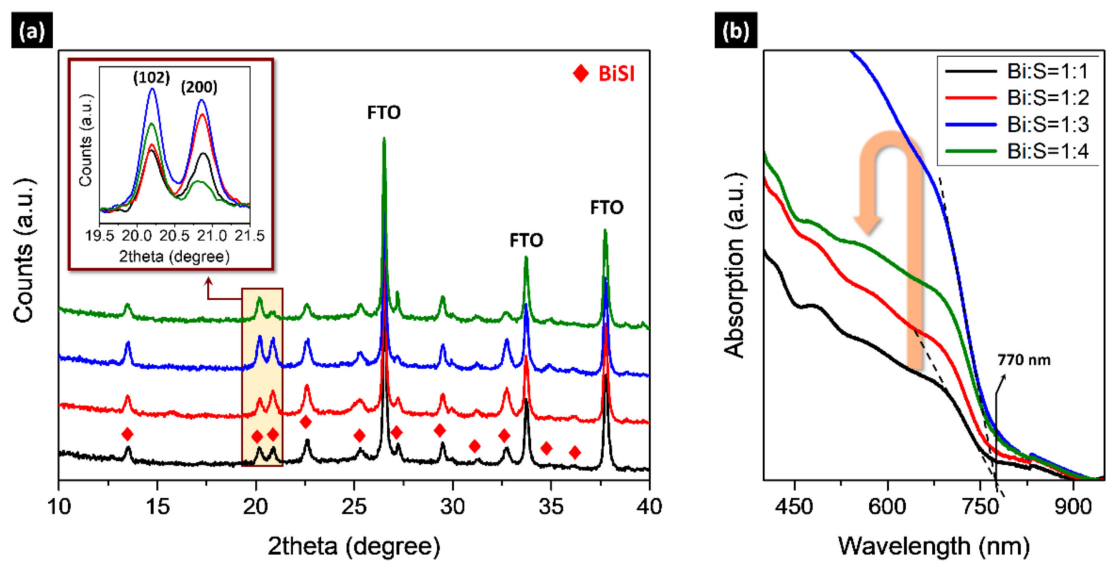

Figure 2. (a) XRD patterns and (b) absorption spectra of the BiSI thin films fabricated $\mathrm{Bi}_{2} \mathrm{O}_{3}-\mathrm{TU}$ solution of various Bi:S molar ratios. All samples were fabricated on $\mathrm{TiO}_{2}-\mathrm{BL} / \mathrm{FTO}$.

The different BiSI formation by the Bi:S molar ratio may be explained in terms of the contribution of excess TU to BiSI formation. The TU as a sulfur source should be sufficiently supplied at each step to compensate for the loss of volatile TU at our annealing temperature of $200{ }^{\circ} \mathrm{C}$. In addition, an excess TU may contribute to stabilizing the Bi-TU complex in the solution [11,20], enabling a stable supply of S. Thus, the BiSI formation is more enhanced as the more TU is supplied as shown in Figure 2. However, at a highly excess TU condition, organic residues derived from residual TU may interfere with BiSI formation. As a result, the BiSI with maximum intensity can be obtained at the specific ratio of $\mathrm{Bi}: \mathrm{S}=1: 3$. Interestingly, the optimum ratio of $\mathrm{Bi}: \mathrm{S}(1: 3)$ is same as that of $\mathrm{Sb}: \mathrm{S}$ used for SbSI [11], although the solution method and the material are quite different. Besides, the TU plays a similar role in forming the crystalline phase in both materials. Therefore, we can expect that the optimum ratio condition may be useful in the formation of other $\mathrm{Sb} / \mathrm{Bi}$ chalcohalides, such as SbSeI and BiSeI.

The BiSI formation could also be controlled by adjusting the repetition of step I. The samples were fabricated under the same conditions as the sample of Figure 1, except for the number of repetitions of step I. As shown in Figure 3a,b, and Supplementary Figure S2, $\mathrm{Bi}_{2} \mathrm{~S}_{3}$ bundles consisting of nanorods with 10-30 nm diameters, were formed after step I and converted to BiSI nanorods in step II. The diameter (60-100 nm) of BiSI nanorods were larger than that of the $\mathrm{Bi}_{2} \mathrm{~S}_{3}$ nanorods, suggesting that the $\mathrm{Bi}_{2} \mathrm{~S}_{3}$ aggregates to form BiSI nanorods during step II. These results indicate that the BiSI film consists of nanorods rather than a continuous film. As the number of repetitions increased, the number of $\mathrm{Bi}_{2} \mathrm{~S}_{3}$ bundles increased, as shown in Figure 3a. As a result, more BiSI nanorods were formed in step II. Simultaneously, the thickness of the BiSI nanorod film was increased from 210 to $657 \mathrm{~nm}$ (Supplementary Table S2). Thus, a large number of nanorods covered the entire surface after three repetitions (Figure $3 b$ and Supplementary Figure S3). This increased number of nanorods was supported by enhanced absorption with increasing repetitions (Figure 3c). To further confirm this, structures were investigated with XRD. The results are shown in Figure $3 \mathrm{~d}$. Up to three repetitions (I-\#3), the peak intensity of BiSI phase increased, but decreased when step I was repeated four times (I-\#4). Simultaneously, the $\mathrm{Bi}_{2} \mathrm{~S}_{3}$ phase appeared at I-\#3 and its intensity was further enhanced at I-\#4. This result indicates that some of $\mathrm{Bi}_{2} \mathrm{~S}_{3}$ remained unconverted to $\mathrm{BiSI}$ in the two samples for I-\#3 and I-\#4. Thus, improved absorption observed at I-\#3 and I-\#4 can be explained by the contribution of $\mathrm{BiSI}$ and $\mathrm{Bi}_{2} \mathrm{~S}_{3}$ rather than just BiSI, because both have similar absorption edges as shown in Figure 1c. Therefore, pure-phase BiSI with maximum intensity could be obtained when step I was repeated twice. 


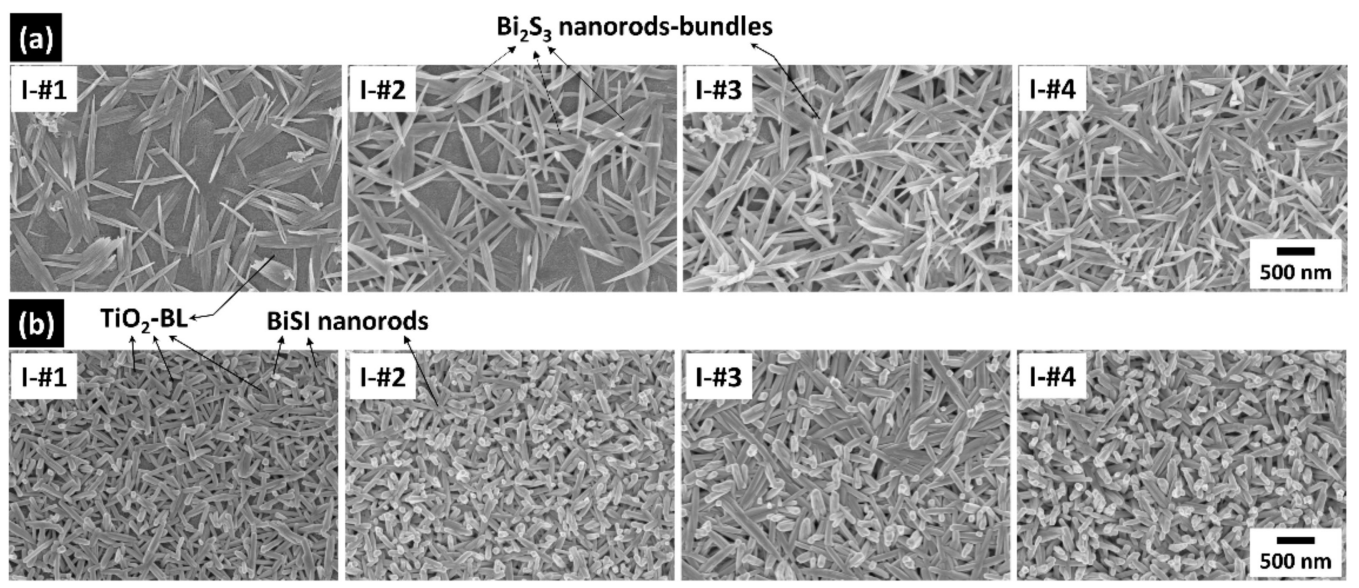

(c)

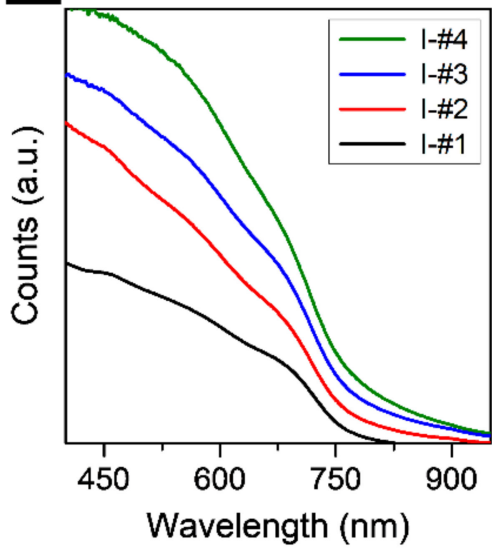

(d)

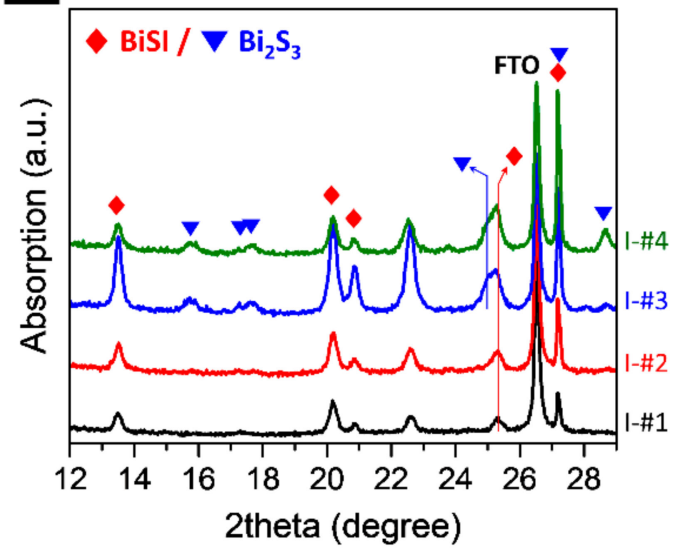

Figure 3. Effects of the number of repetitions of step I: Field emission scanning electron microscopy (FESEM) surface images of the samples prepared after (a) step I; (b) step II; (c) absorption spectra and (d) XRD patterns of the samples prepared after step II. In figures, I-\#number indicates the number of repetitions in step $\mathrm{I}$. The samples were fabricated on $\mathrm{TiO}_{2}-\mathrm{BL} / \mathrm{FTO}$ using the $\mathrm{Bi}_{2} \mathrm{O}_{3}$-TU solution (Bi:S = 1:3 ratio).

Note that the repetition of step II did not cause further conversion of $\mathrm{Bi}_{2} \mathrm{~S}_{3}$ to $\mathrm{BiSI}$, formed in the I-\#3 and I-\#4 samples, but resulted in BiOI formation (Supplementary Figure S4). To figure out the reason why BiSI was no longer converted from the $\mathrm{Bi}_{2} \mathrm{~S}_{3}$ in I-\#3 and I-\#4, we examined their morphology and compared it with those obtained from the I-\#1 and I-\#2 samples. As show in Figure $3 a$ and Supplementary Figure S2, the $\mathrm{Bi}_{2} \mathrm{~S}_{3}$ bundles formed after step I, in I-\#1 and I-\#2, did not cover the entire surface of underlying $\mathrm{TiO}_{2}-\mathrm{BL}$, revealing a portion of the $\mathrm{TiO}_{2}-\mathrm{BL}$ surface. The converted samples show the nanorods randomly grown on the $\mathrm{TiO}_{2}-\mathrm{BL} / \mathrm{FTO}$ substrate (Figure 4a). As a result, the nanorods were grown from 210 to $410 \mathrm{~nm}$ as step I was repeated (Table S2). In contrast, the $\mathrm{Bi}_{2} \mathrm{~S}_{3}$ bundles were intricately intertwined so that the underlying $\mathrm{TiO}_{2}-\mathrm{BL}$ surface was not revealed in I-\#3 and I-\#4 (Figure 3a). The samples obtained from such intertwined bundles exhibit a two-layered structure, with nanorods on the upper layer and aggregated nanostructures on the lower layer (Figure $4 \mathrm{~b}$ ). The thickness of each layer is very similar in I-\#3 and I-\#4 samples, as revealed in Table S2, suggesting that the multiple coating did not affect the BiSI growth. By comparing morphologies and structures, it can be inferred that the nanorods in the upper layer and nanostructures in the lower layer mainly consisted of BiSI and $\mathrm{Bi}_{2} \mathrm{~S}_{3}$, respectively. This was confirmed by the grazing incident XRD (GIXRD) measurement (Supplementary Figure S5). These results indicate that the intertwined $\mathrm{Bi}_{2} \mathrm{~S}_{3}$ bundles prevented the $\mathrm{BiI}_{3}$ solution from reaching the bottom of the $\mathrm{Bi}_{2} \mathrm{~S}_{3}$ layer, in the I-\#3 and I-\#4 samples. Thus, the $\mathrm{Bi}_{2} \mathrm{~S}_{3}$ at the bottom could react with $\mathrm{BiI}_{3}$, leaving unconverted $\mathrm{Bi}_{2} \mathrm{~S}_{3}$ at the bottom. As a 
result, the BiSI nanorods were formed in the upper layer, in which the $\mathrm{BiI}_{3}$ solution can actively react, whereas the nanostructures mainly composed of $\mathrm{Bi}_{2} \mathrm{~S}_{3}$ are formed in the lower layer.

(a)

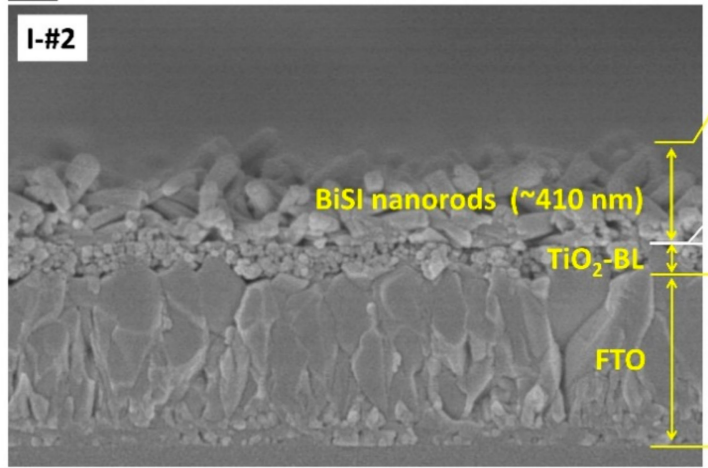

\section{(b)}

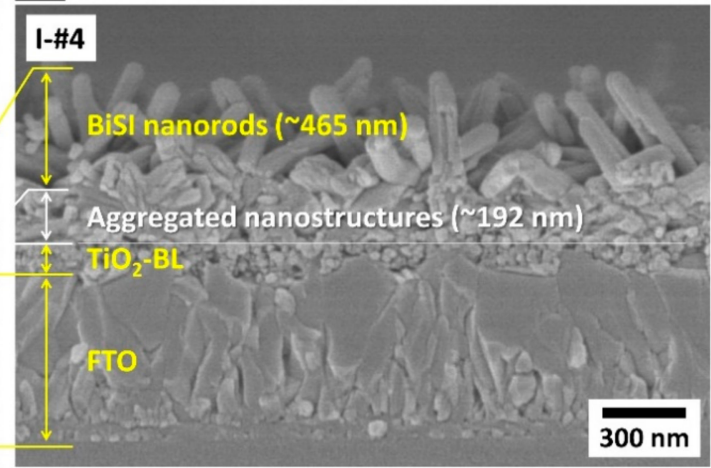

Figure 4. Cross-sectional FESEM images of (a) I-\#2 and (b) I-\#4 samples prepared after step II.

To investigate the electronic structure of the BiSI thin film, we measured ultraviolet photoemission spectroscopy (UPS) spectra, as shown in Figure 5a. From the two spectra of the cutoff and valence band edge regions, we could obtain the cutoff energy $E_{\text {cutoff }}$ and difference $\Delta=E_{V}-E_{F}$; where $E_{V}$ is the valence band maximum and $E_{F}$ is Fermi level. These were 16.7 and $1.3 \mathrm{eV}$, respectively. Correspondingly, we could calculate $E_{F}, E_{V}$, and conduction band minimum (CBM, $\left.E_{C}\right)$, which were $4.5,5.9$, and $4.3 \mathrm{eV}$, respectively, based on the relation of $E_{F}=\mathrm{h} v-\left(E_{\text {cutoff }}-E_{V A C}\right)\left(E_{V A C}\right.$ : vacuum level energy) and $E_{G}$. From these results, it was revealed that the BiSI behaves like a n-type semiconductor, consistent with a previous study [8], because $E_{F}$ is located close to $E_{C}$. Based on this measurement, we drew an energy-level diagram for the as-fabricated BiSI nanorods film, as shown in Figure $5 b$. We also included other widely used layers to examine its applicability to solar cells. For a solar cell that constructed with FTO, $\mathrm{TiO}_{2}$, poly(3-hexylthiophene) (P3HT) as the conducting oxide, electron transporting layer (ETL), and hole transporting material (HTM), respectively, we expected very poor device performance. A preliminary result confirmed that this device did not work properly (Supplementary Figure S6 and Table S2). These are for the following two reasons: First, it is very difficult for electrons to transfer from the $\mathrm{CBM}$ of $\mathrm{BiSI}$ to the $\mathrm{CBM}$ of $\mathrm{TiO}_{2}$ because the $\mathrm{CBM}$ of $\mathrm{BiSI}$ is located below that of $\mathrm{TiO}_{2}$. Second, the highest occupied molecular orbitals (HOMO) level of P3HT is located at $5.1 \mathrm{eV} ; \sim 0.6 \mathrm{eV}$ lower than $E_{F}$ of BiSI. Thus, the maximum open circuit voltage $V_{O C}$ is limited to $0.6 \mathrm{eV}$. Therefore, to achieve a high device efficiency, these two issues must be solved.
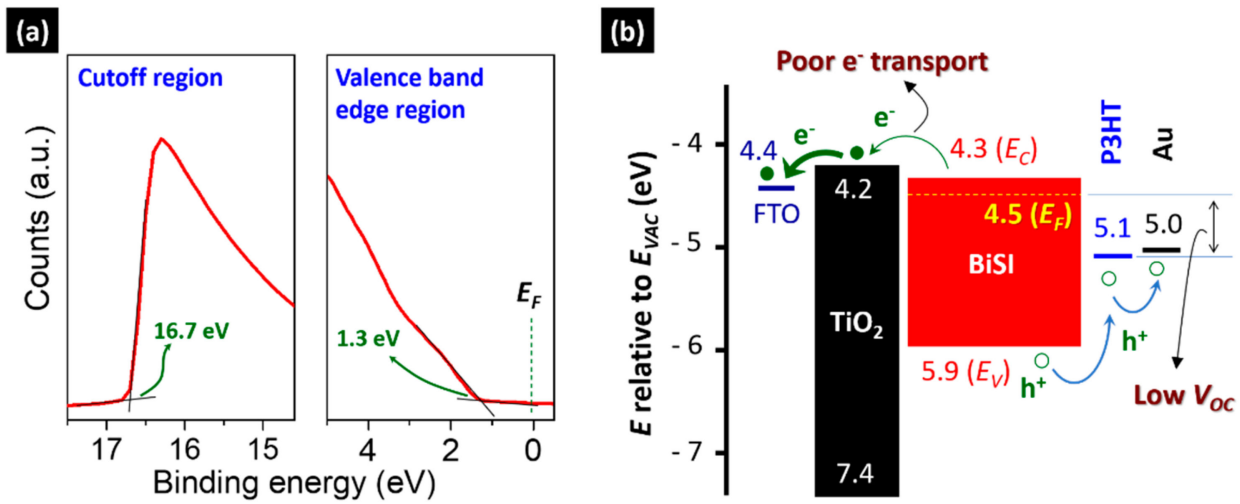

Figure 5. (a) UPS spectra of the cut-off and valence band edge region for the BiSI nanorods film, and (b) the derived energy-level band diagram. For comparison, a conducting oxide (FTO), ETL $\left(\mathrm{TiO}_{2}\right)$, HTM (P3HT), and electrode (Au) were drawn based on a previous study [11]. 
The first issue can be addressed by using an alternative ETL that has a CBM lower than that of BiSI. Material engineering via doping/alloying for shifting the CBM of BiSI could be another solution for solving this, while maintaining the $\mathrm{TiO}_{2}$ ETL. To address the second issue, a HTM with a deep HOMO level should be used, such as 3,3'-dimethoxybenzidine moieties (S9, $5.5 \mathrm{eV}$ ) [21], poly(9,9-di-n-octylfluorenyl-2,7-diyl) (F8, $5.8 \mathrm{eV})$ [5,9] and poly(9,9-dioctylfluorene-alt-benzothiadiazole) (F8BT, $5.9 \mathrm{eV}$ ) [22]. Very recently, Tiwari et al. addressed these issues by using $\mathrm{SnO}_{2}$ and F8 as the ETL and HTM, respectively, and achieved the best device efficiency (1.32\%) in BiSI solar cells [9]. This efficiency is a significant improvement compared to $0.012 \%$ for the solar cell fabricated by Hahn et al [8]. Despite great progress in performance, the best efficiency is still very far below that of $\mathrm{Pb}$ perovskites solar cells. Therefore, several other factors, such as defects, crystalline orientation, device architecture, and material engineering, should also be considered to further enhance the performance $[5,6]$.

\section{Conclusions}

BiSI films with $E_{G}=1.61 \mathrm{eV}$ were fabricated via our two-step solution process which consists of $\mathrm{Bi}_{2} \mathrm{~S}_{3}$ formation and its conversion to BiSI at a low temperature of $200{ }^{\circ} \mathrm{C}$. Through controlling experimental parameters, the best crystallinity of BiSI could be obtained with the molar ratio of $\mathrm{Bi}: \mathrm{S}=1: 3$ and two repetitions of step I. As-fabricated BiSI showed nanorods, $60-100 \mathrm{~nm}$ in diameter, grown randomly on $\mathrm{TiO}_{2}$-BL/FTO, rather than a continuous film. In addition, we found that the BiSI behaved like a n-type semiconductor with $E_{F} 4.5 \mathrm{eV}, E_{V} 5.9 \mathrm{eV}$, and $E_{C} 4.3 \mathrm{eV}$. Our work is expected to contribute to improving the performance of Bi-based chalcohalide solar cells and to provide some clues for developing low-cost and environment-friendly solar cells.

Supplementary Materials: The following are available online at http://www.mdpi.com/2079-4991/9/12/1650/s1, Table S1: comparison of costs for fabrication of BiSI and $\mathrm{CH}_{3} \mathrm{NH}_{3} \mathrm{PbI}_{3}$, Figure S1: XRD pattern of bare sample and treated with NMP, Figure S2: high magnification FESEM surface images of the sample prepared after step I and step II, Figure S3: low magnification FESEM surface image of the BiSI nanorods (I-\#4 sample) formed on $\mathrm{TiO}_{2}$-BL/FTO, Table S2: thickness of the BiSI films shown in Figure 3 and Figure 4, Figure S4: effect of step II repetitions on the sample (I-\#3) shown in Figure 3, Figure S5: GIXRD patterns as a function of incident angle $\alpha$ and normal XRD pattern of the sample shown in Figure 4b, Figure S6. cross-sectional FESEM images of the solar cells based on (a) BiSI and (b) Pb perovskite, Table S2. Device parameters of two samples are shown in Figure S6.

Author Contributions: Supervision, methodology, investigation, formal analysis, data curation, and writing —original draft, review \& editing, Y.C.C.; investigation, formal analysis, and writing-review \& editing, E.H.

Funding: This work was supported by the National Research Foundation of Korea (NRF) grant funded by the Korea government (MSIT) (No. 2019R1F1A1049014). This work was also supported by the DGIST R\&D program of the Ministry of Science and ICT, Republic of Korea (No. 19-ET-01).

Conflicts of Interest: The authors declare no conflict of interest.

\section{References}

1. Jena, A.K.; Kulkarni, A.; Miyasaka, T. Halide Perovskite Photovoltaics: Background, Status, and Future Prospects. Chem. Rev. 2019, 119, 3036-3103. [CrossRef]

2. Jung, E.H.; Jeon, N.J.; Park, E.Y.; Moon, C.S.; Shin, T.J.; Yang, T.-Y.; Noh, J.H.; Seo, J. Efficient, Stable and Scalable Perovskite Solar Cells Using Poly(3-hexylthiophene). Nature 2019, 567, 511. [CrossRef]

3. Chung, J.; Shin, S.S.; Kim, G.; Jeon, N.J.; Yang, T.-Y.; Noh, J.H.; Seo, J. Impact of Electrode Materials on Process Environmental Stability of Efficient Perovskite Solar Cells. Joule 2019, 3, 1977-1985. [CrossRef]

4. Ganose, A.M.; Savory, C.N.; Scanlon, D.O. Beyond Methylammonium Lead Iodide: Prospects for The emergent Field of $n s^{2}$ Containing Solar Absorbers. Chem. Commun. 2016, 53, 20-44. [CrossRef]

5. Ganose, A.M.; Butler, K.T.; Walsh, A.; Scanlon, D.O. Relativistic Electronic Structure and Band Alignment of BiSI and BiSeI: Candidate Photovoltaic Materials. J. Mater. Chem. A 2016, 4, 2060-2068. [CrossRef]

6. Ganose, A.M.; Matsumoto, S.; Buckeridge, J.; Scanlon, D.O. Defect Engineering of Earth-Abundant Solar Absorbers BiSI and BiSeI. Chem. Mater. 2018, 30, 3827-3835. [CrossRef] [PubMed] 
7. Shi, H.; Ming, W.; Du, M.-H. Bismuth Chalcohalides and Oxyhalides as Optoelectronic Materials. Phys. Rev. B 2016, 93, 104108. [CrossRef]

8. Hahn, N.T.; Rettie, A.J.E.; Beal, S.K.; Fullon, R.R.; Mullins, C.B. n-BiSI Thin Films: Selenium Doping and Solar Cell Behavior. J. Phys. Chem. C 2012, 116, 24878-24886. [CrossRef]

9. Tiwari, D.; Cardoso-Delgado, F.; Alibhai, D.; Mombrú, M.; Fermín, D.J. Photovoltaic Performance of Phase-Pure Orthorhombic BiSI Thin-Films. ACS Appl. Energy Mater. 2019, 2, 3878-3885. [CrossRef]

10. Kunioku, H.; Higashi, M.; Abe, R. Low-Temperature Synthesis of Bismuth Chalcohalides: Candidate Photovoltaic Materials with Easily, Continuously Controllable Band Gap. Sci. Rep. 2016, 6, 32664. [CrossRef]

11. Choi, Y.C.; Hwang, E.; Kim, D.-H. Controlled Growth of SbSI Thin Films from Amorphous $\mathrm{Sb}_{2} \mathrm{~S}_{3}$ for low-Temperature Solution Processed Chalcohalide Solar Cells. APL Mater. 2018, 6, 121108. [CrossRef]

12. Grigas, J.; Talik, E.; Adamiec, M.; Lazauskas, V.; Nelkinas, V. XPS and Electronic Structure of Quasi-one -Dimensional BiSI Crystals. J. Electron. Spectros. 2006, 153, 22-29. [CrossRef]

13. McCarthy, C.L.; Brutchey, R.L. Solution Processing of Chalcogenide Materials Using Thiol-amine "alkahest" Solvent Systems. Chem. Commun. 2017, 53, 4888-4902. [CrossRef] [PubMed]

14. Zhang, T.; Zhang, L.; Yin, Y.; Jiang, C.; Li, S.a.; Zhu, C.; Chen, T. A Thiol-amine Mixture for Metal Oxide towards Device Quality Metal Chalcogenides. Sci. China Mater. 2019, 62, 899-906. [CrossRef]

15. Choi, Y.C.; Seok, S.I.; Hwang, E.; Kim, D.-H. Key Factors Affecting the Performance of $\mathrm{Sb}_{2} \mathrm{~S}_{3}$-sensitized Solar Cells During an $\mathrm{Sb}_{2} \mathrm{~S}_{3}$ Deposition via $\mathrm{SbCl}_{3}$-thiourea Complex Solution-processing. J. Vis. Exp. 2018, 137, e58062. [CrossRef]

16. Wang, Y.; Chen, J.; Jiang, L.; Liu, F.; Lai, Y.; Li, J. Characterization of $\mathrm{Bi}_{2} \mathrm{~S}_{3}$ Thin Films Synthesized by An Improved Successive Ionic Layer Adsorption and Reaction (SILAR) Method. Mater. Lett. 2017, 209, 479-482. [CrossRef]

17. Bernechea, M.; Cao, Y.; Konstantatos, G. Size and Bandgap Tunability in $\mathrm{Bi}_{2} \mathrm{~S}_{3}$ Colloidal Nanocrystals and Its Effect in Solution Processed Solar Cells. J. Mater. Chem. A 2015, 3, 20642-20648. [CrossRef]

18. Groom, R.A.; Jacobs, A.; Cepeda, M.; Drummey, R.; Latturner, S.E. Structural and Optical Properties of Sb-Substituted BiSI Grown from Sulfur/Iodine Flux. Inorg. Chem. 2017, 56, 12362-12368. [CrossRef]

19. Ran, Z.; Wang, X.; Li, Y.; Yang, D.; Zhao, X.-G.; Biswas, K.; Singh, D.J.; Zhang, L. Bismuth and Antimony-Based Oxyhalides and Chalcohalides As Potential Optoelectronic Materials. npj Comput. Mater. 2018, 4, 14. [CrossRef]

20. Su, B.; Choy, K. Microstructure and Properties of The CdS Thin Films Prepared by Electrostatic Spray Assisted Vapour Deposition (ESAVD) Method. Thin Solid Films 2000, 359, 160-164. [CrossRef]

21. Gawlinska, K.; Iwan, A.; Starowicz, Z.; Kulesza-Matlak, G.; Stan-Glowinska, K.; Janusz, M.; Lipinski, M.; Boharewicz, B.; Tazbir, I.; Sikora, A. Searching of New, Cheap, Air- and Thermally Stable Hole Transporting Materials for Perovskite Solar Cells. Opto-Electron. Rev. 2017, 25, 274-284. [CrossRef]

22. Zhang, Y.; Blom, P.W. Electron and Hole Transport in Poly(fluorene-benzothiadiazole). Appl. Phys. Lett. 2011, 98, 143504. [CrossRef]

(C) 2019 by the authors. Licensee MDPI, Basel, Switzerland. This article is an open access article distributed under the terms and conditions of the Creative Commons Attribution (CC BY) license (http://creativecommons.org/licenses/by/4.0/). 